\title{
PEDAGOGIA, MATEMÁTICA E ESTÁGIO EM DOCÊNCIA: a experiência a partir de uma tríade formativa
}

\author{
MARIA DO CARMO ALVES DA CRUZ \\ Universidade Federal do Maranhão (UFMA). Mestra em Educação (UFMA). Doutoranda \\ em Educação em Ciências e Matemática - Rede Amazônica de Educação em Ciências e \\ Matemática-REAMEC. Licenciada em Pedagogia. Professora do curso de Pedagogia, da \\ Universidade Federal do Maranhão, pesquisa formação de professores que ensinam Matemática, \\ Estágio em Docência e Ensino de Matemática na Educação Infantil e Anos Iniciais do Ensino \\ Fundamental. ORCID: 0000-0002-7928-1284.E-mail: docarmo_cruz@hotmail.com
}

\section{NEUZA BERTONI PINTO}

Universidade Federal de Mato Grosso (UFMT). Doutora em Educação (USP). Professora Titular aposentada pela Pontifícia Universidade Católica do Paraná. Professora Colaboradora do Programa de Pós Graduação em Educação em Ciências e Matemática - PPGECEM- REAMEC - UFMT. Vice Presidente e Pesquisadora do Ghemat Brasil e Pesquisadora do Ghemat Paraná.

ORCID: 0000-0002-9224-3020. E-mail: neuzabertonip@gmail.com

\section{SUZANA ANDRÉIA SANTOS COUTINHO}

Secretaria Municipal de Educação-SEMED de São Luís-MA. Mestra em Educação (UFMA). Licenciada em Pedagogia pela Universidade Federal do Maranhão. Professora da Rede Municipal de Educação de São Luís- MA. ORCID: 0000-0001-8590-0419.

E-mail: suzanasantoscoutinho@outlook.com 


\section{PEDAGOGIA, MATEMÁTICA E ESTÁGIO EM DOCÊNCIA: a experiência a partir de uma tríade formativa}

A necessidade de pensar o lugar ou o não-lugar reservado à educação matemática, seja nos documentos legais, seja nos currículos, impulsiona cada vez mais pesquisadores a identificarem o porquê das defasagens, considerando que desde os primórdios da humanidade até a modernidade, a matemática é vista, num contexto nacional, como inflexível e causadora de traumas em crianças e adolescentes. Considerando este cenário, esta pesquisa objetiva socializar as experiências vivenciadas durante o estágio em docência em Ciências e Matemática, no doutorado em Educação, organizado a partir do conceito de tríade formativa no curso de Pedagogia. A metodologia utilizada é qualitativa, precedida de revisão bibliográfica, utilizando como método a investigação da própria prática na perspectiva de Ponte (2002), Lima e Nacarato (2009), tendo como interlocutores estudantes de Pedagogia e Professores dos Anos Iniciais do Ensino Fundamental. Para viabilizá-la, enquanto o aporte teórico considera Zabalza (2014) para discutir estágio; as discussões sobre experiência foram ancoradas em Bondía (2002); Fiorentino e Lorenzato (2006) sobre educação matemática; o conceito de tríade formativa é utilizado a partir de Zanon (2003) e sobre formação de professores Tardif (2008), dentre outros, além dos documentos oficiais, Brasil (2002; 2006; 2015; 2017 e 2019) também foram incorporadas às análises. A pesquisa mostrou que as aprendizagens empreendidas, por meio dos diálogos, integram a constituição do ser docente, evidenciando o quão válido é a aproximação das escolas com a universidade pública. O contato dinâmico e flexível possibilita construir espaços de reflexão-ação-reflexão para qualificar as práticas pedagógicas, tanto das estudantes, dos docentes da educação básica, quanto dos docentes formadores.

Palavras-chave: Estágio em docência. Tríade Formativa. Ensino de Matemática.

\section{PEDAGOGY, MATHEMATICS AND TRAINING IN TEACHING: the experience from a training trade}

The need to think about the place or non-place reserved for mathematics education, whether in legal documents or in curricula, drives more and more researchers to identify why of lags, considering that from the beginning until modernity, mathematics is seen, in a national context, as inflexible and causing trauma to children and adolescents. Considering this scenario, this research aims to socialize the experiences lived during the internship in teaching in Sciences and Mathematics, in the $\mathrm{PhD}$ in Education, organized from the concept of formative triad in the Pedagogy course. The methodology used is applied, preceded by a bibliographic review, using investigation of own practice as a method, Ponte (2002), Lima and Nacarato (2009) with the corpus of research graduates in Pedagogy and Teachers of the Early and Final Years of Early Childhood Education. To make it feasible, as a theoretical contribution, Zabalza (2014) was used to discuss internship; the discussions about experience were anchored in Bondía (2002); Fiorentino and Lorenzato (2006) on mathematics education; the concept of formative triad is used from Zanon (2003) and on teacher training Tardif (2008), among others, in addition to official documents, Brazil (2002; 2006; 2015; 2017 and 2019). The research showed that the exchange made through dialogues, integrates 
our construction as teachers, making us realize how valid the approximation of schools with the public university is. The dynamic and flexible contact makes it possible to build spaces for reflection-actionreflection to qualify the pedagogical practices, both of the licentiates, as well as of the teachers working in the basic education classroom, in addition to the participating trainers.

Keywords: Teaching internship. Formative Triad. Mathematics teaching.

\section{PEDAGOGÍA, MATEMÁTICAS Y FORMACIÓN EN LA ENSEÑANZA: experiencia de una tríada formativa}

La necesidad de pensar en el lugar o no lugar reservado para la educación matemática, sea en documentos legales, sea en planes de estudio, impulsa cada vez más investigadores a identificar la razón de las brechas, considerando desde el principio hasta la modernidad, se mira la matemática, en un contexto nacional, como inflexible y causante de traumas en niños y adolescentes. Teniendo en cuenta este escenario, esta investigación tiene como objetivo socializar las experiencias vividas durante la formación en la enseñanza de Ciencias y Matemáticas, en el doctorado en Educación, organizada con base en el concepto de tríada formativa del curso de Pedagogía. La metodología utilizada es aplicada, precedida de una revisión bibliográfica, utilizando la investigación en acción como método, teniendo como corpus de investigación graduadas en pedagogía y docentes de los primeros y últimos años de la educación de la primera infancia. Para hacerlo posibles, como contribución teórica, recurrimos a Zabalza (2014) para discutir pasantías; las discusiones sobre la experiencia se anclaron en Bondía (2002); Fiorentino y Lorenzato (2006) sobre educación matemática; El concepto de tríada formativa se utiliza en Zanon (2003) y sobre los mestros con Tardif (2008), entre otros, además de los documentos oficiales, Brasil (2002; 2006; 2015; 2017 y 2019). La investigación mostró que el intercambio realizado a través de diálogos integra nuestra construcción como docentes, haciéndonos dar cuenta de cuán válida es la aproximación de las escuelas con la universidad pública. El contacto dinámico y flexible permite construir espacios de reflexión-acción-reflexión para calificar las prácticas pedagógicas, tanto de los licenciados como de los maestros que trabajan en el aula de educación básica, además de los capacitadores participantes.

Palabras clave: Pasantía docente. Tríada Formativa. Enseñanza de la Matemática. 


\section{PEDAGOGIA, MATEMÁTICA E ESTÁGIO EM DOCÊNCIA: a experiência a partir de uma tríade formativa}

\section{Introdução}

Esta pesquisa é um recorte da experiência do Estágio em docência, componente das atividades do doutorado, em curso, no Programa de Pós-Graduação em Educação em Ciências e Matemática - PPGECEM - UFMT, da Rede Amazônica de Educação em Ciências e Matemática - REAMEC. No tocante às especificidades, as atividades foram desenvolvidas durante o segundo semestre de 2019, no curso de Pedagogia da Universidade Federal do Maranhão - UFMA, campus Dom Delgado, na cidade de São Luís, estado do Maranhão.

Revisitando o contexto histórico de formação docente, no Maranhão, identificamos que embora tenha havido tentativas durante todo o século XIX, somente teve sua institucionalização em sua última década, através do Decreto $\mathrm{n}^{\circ} 21$, de 15 de abril de 1890 , conforme determina em seu artigo $7^{\circ}$ : "fica criada nesta capital uma Escola Normal" (MARANHÃO, 1890).

A partir desse feito, sessenta e dois anos depois, foi criado o Curso de Pedagogia da Universidade Federal do Maranhão, vinculado à criação da Faculdade de Filosofia de São Luís, fundada em 15 de agosto de 1952, tendo sua autorização de funcionamento instituída pelo Decreto $\mathrm{n}^{\circ} 32.606$, de 23 de abril de 1953 (BRASIL, 1953). O reconhecimento do Curso junto às instâncias deliberativas e representativas efetivou-se quatro anos mais tarde, através do Decreto No 39.663, de 28 de julho de 1956 (BRASIL, 1956). Diante deste cenário, passadas mais de seis décadas desde sua implementação, vários decretos e resoluções orientaram a formação do Pedagogo, incluindo muitas alterações na proposta inicial de formação. Entretanto, apesar das alterações e dos avanços, percebemos uma lacuna para com a matemática, bem como sua pouca visibilidade, segundo revisão bibliográfica e análises prévias.

Nesta perspectiva, podemos nos questionar: qual lugar é reservado à matemática nos currículos dos cursos de Pedagogia? Para tentar responder, buscamos subsídios na 
sociologia, para qual lugar significa centro de significações construído pela experiência-produto da existência humana, sendo criado pelos seres humanos para os seus projetos (TUAN, 1983). Outra definição, entende-o como somatório das dimensões simbólicas, emocionais, culturais, políticas e psicológicas (BUTTIMER, 1985). Desse modo, a partir dessas assertivas sobre lugar, percebermos que no percurso formativo das ${ }^{1}$ estudantes de Pedagogia, existe a sensação da matemática ocupar um não-lugar. Augé (1994, p. 167) afirma que “[...]o não-lugar é o espaço dos outros sem a presença dos outros".

Considerando essas questões norteadoras, inicialmente, o estágio apresenta-se necessário para transformar este não-lugar em lugar, aliás, é de fundamental importância por se tratar do ensino da matemática na formação da Pedagoga. Tal assertiva justifica-se considerando o déficit na formação inicial destas profissionais, o que faz com que a temática necessite uma análise minuciosa. Outras problemáticas podem interferir nos percursos formativos, como a permanência dos baixos índices de aprendizagem em matemática; o tratamento dado à área pelos municípios do estado, nos currículos dos cursos de Pedagogia, tendo em vista as intencionalidades e seus efeitos como interrelacionados e consequentes.

A metodologia utilizada é qualitativa, precedida de revisão bibliográfica, utilizando como método a investigação da própria prática, ancorado em Ponte (2002, p. 2) que ratifica,
A investigação sobre a sua prática é, por consequência, um processo fundamental de construção do conhecimento sobre essa mesma prática e, portanto, uma actividade de grande valor para o desenvolvimento profissional dos professores que nela se envolvem activamente.

Nesta perspectiva, Nacarato (2009), aponta três razões para justificar a pesquisa da própria prática, permite ao docente apropriar-se como protagonista do desenvolvimento curricular e profissional; fortalece o desenvolvimento profissional e atua como transformador da cultura escolar; evidencia elementos que promovem maior compreensão dos problemas educacionais e da cultura profissional.

Portanto, no tocante à estruturação deste texto, após esta introdução traremos considerações sobre o ensino de matemática no curso de Pedagogia, à luz da legislação brasileira; em seguida,

1 Optamos por utilizar a terminologia no gênero feminino porque as mulheres constituem a maioria frequente nos cursos de Pedagogia. 
a experiência do estágio doutoral, especificamente sobre as possibilidades de aprendizagem utilizando a tríade Pedagogia-Matemática-Estágio. Continuamos com as discussões das relações entre universidade e Educação Básica, afunilando as discussões no ciclo de alfabetização: o olhar de quem já ocupou os dois lugares, encerrando com as considerações finais do apanhado teórico e observações, seguidas das referências.

\section{O ensino de matemática no curso de pedagogia}

Diante de um cenário de mais de oitenta anos da criação do primeiro curso de Pedagogia no Brasil, e atendendo as necessidades de cada época, os decretos e resoluções, bem como toda legislação que orienta a formação do Pedagogo, são constantemente reformulados. Entretanto, cabe destacar que nessas mudanças a matemática é a que menos tem se modificado neste interstício, ou seja, entendemos que isso se justifica pela pouca visibilidade.

Para pensar o lugar da matemática nas reformulações, ou o seu não-lugar, é preciso historicizar. Nesse movimento, é possível encontrar diversas tentativas de reformas curriculares, Santos e Matos (2017) apresentam resumos de algumas citando a professora Martha Maria de Souza Dantas, em um Congresso na Bahia no ano de 1955, informando que:

Muitos foram os congressos e grupos de debates que seguiram com essa mesma linha de questionamentos sobre as reformas curriculares no Brasil, até que nos anos 1990, após a aprovação da Lei de Diretrizes Bases da Educação Nacional - LDBEN (BRASIL, 1996), inicia-se uma discussão sobre propostas curriculares que atendessem a realidade do país, e surge nesse cenário os Parâmetros Curriculares Nacionais (BRASIL, 1997) como proposta de nortear o ensino na educação básica [...] e a proposta apresentada de forma verticalizada seguiu por quase 20 anos sem ampla divulgação, mas passando também por revisões que passaram à margem nas escolas. (SANTOS; MATOS, 2017, p. $15)$.

A partir do que discute os autores, a ausência de um amplo debate, com um percentual significativo de docentes da área, os quais estão no atendimento direto, provoca um certo desencanto pelas políticas públicas e programas, cujo objetivo seria uma ação docente efetiva, e que vai na contramão do que é estabelecido pelo Estado brasileiro, enquanto legislação específica. Nos primeiros anos deste século, foi sancionada a Resolução $n^{\circ}$ 01, datada de fevereiro de 2002, na qual o Art. $3^{\circ}$ determina que a formação de professores que atuarão nas diferentes etapas e 
modalidades da educação básica, observará princípios norteadores que considerem os conteúdos, como meio e suporte para a constituição das competências referentes ao domínio dos conteúdos a serem socializados, aos seus significados em diferentes contextos e sua articulação interdisciplinar (BRASIL, 2002).

Quatro anos após esse documento, a Resolução do Conselho Nacional de Educação - CNE/ $\mathrm{CP}, \mathrm{N}^{\mathrm{o}} 1$, de 15 de maio de 2006, instituiu as Diretrizes Curriculares Nacionais para o Curso de Graduação em Pedagogia e licenciatura; no Art. $5^{\circ}$ afirma que o egresso desse curso deverá estar apto a ensinar Matemática de forma interdisciplinar e adequada às diferentes fases do desenvolvimento humano (BRASIL, 2006). A partir desses trechos, essa normativa nos permite um questionamento nuclear: que tratamento a matemática tem recebido nos cursos de Pedagogia, de maneira a garantir seus profissionais sejam capazes de ensiná-la para atender as necessidades do alunado dos anos iniciais?

No que concerne à aprendizagem da matemática nos anos iniciais do ensino fundamental, etapa onde a pedagoga é a responsável pela ministração desses conteúdos, as pesquisas em Educação Matemática têm revelado grandes dificuldades de aprendizagem pelas crianças. Diante deste cenário, é importante identificar as razões dos entraves, uma vez que tanto a LDB n ${ }^{\circ}$ 9394/96 quanto a Resolução CNE/CP Nº 1, de 15 de maio de 2006, reiteram a necessidade de uma formação sólida para que as pedagogas possam exercer a docência da melhor forma, utilizando os conhecimentos matemáticos para atingir objetivos estabelecidos para a Educação Infantil e para os Anos Iniciais do Ensino Fundamental. Para tanto, deve-se observar a estrutura organizacional dos cursos, através dos currículos, identificando as fragilidades de formação matemática inicial, que, via de regra, não é substancial para um ensino efetivo.

Novas diretrizes foram estabelecidas pela Resolução $\mathrm{n}^{\circ} 2$, de $1^{\circ}$ de julho de 2015 , que em seu Art. $7^{\circ}$, estabelece que a formação inicial deve possuir um repertório de informações e habilidades compostos pela pluralidade de conhecimentos teóricos e práticos, baseados em princípios de interdisciplinaridade, contextualização, democratização, pertinência e relevância social, ética e sensibilidade afetiva e estética, de modo a lhe permitir: dominar os conteúdos específicos e pedagógicos e as abordagens teórico-metodológicas do seu ensino, de forma interdisciplinar e adequada às diferentes fases do desenvolvimento humano (BRASIL, 2015). 
No tocante à última atualização, existe uma proposição curricular para a formação de professores, que foi estabelecida pela Resolução CNE/CP n ${ }^{\circ}$, de 20 de dezembro de 2019, em que descreve, em seu Art. $7^{\circ}$, VII, "[...] integração entre a teoria e a prática, tanto no que se refere aos conhecimentos pedagógicos e didáticos, quanto aos conhecimentos específicos da área do conhecimento ou do componente curricular a ser ministrado" (BRASIL, 2019, p. 4); de outro lado, no Art. $8^{\circ}$, estabelece o reconhecimento da escola de Educação Básica como lugar privilegiado da formação inicial do professor, da sua prática e da sua pesquisa (BRASIL, 2019).

A instituição de quatro diretrizes que orientam a organização curricular da formação de professores para educação básica, contemplando as pedagogas, em menos de duas décadas, evidenciam a fragilidade das políticas de formação de professores no Brasil, desde sempre marcada pela lógica da continuidade, descontinuidade, comprovando então a ausência de uma política pública de Estado e ratificando aquelas estabelecidas pelos governos no interstício investigado.

Dessa forma, para discutir este currículo é necessário entendê-lo como uma construção histórica e social. Assim, quanto ao percurso histórico, o currículo se caracterizou pela transmissão e legitimação da cultura das classes dominantes, suprimindo importantes expressões culturais, além de excluir as minorias de representação política (mulheres, negros, homossexuais, populações rurais e saberes populares, dentre várias outras). Para Silva (2006), assim como ocorre com outras práticas culturais, as relações de poder são inseparáveis das práticas de significação que constituem e atuam sobre o currículo.

Neste sentido, a Base Nacional Comum Curricular - BNCC, discorre que a formação tem estreita articulação com as mesmas correlações de forças que sustentam a proposta curricular para a educação básica brasileira, ou seja, ela própria foi organizada, em 2017, por especialistas, empresários, intelectuais e uma sociedade civil selecionada para atender aos interesses de pequenos grupos, não entendendo a educação como direito fundamental. "O modo como a BNCC foi elaborada destitui os direitos de aprendizagem da criança” (PASSOS; NACARATO, 2018, p. 120).

Nesta acepção, é evidente que a cobrança chegará nas escolas, nos professores e nas crianças, mas antes de solicitar que tais mudanças sejam efetivadas, é imprescindível assegurar uma formação que possibilite aos professores uma apropriação da proposta, e como este documento ou essas políticas serão desdobrados no cotidiano escolar e nas práticas de sala de aula? Diante disto, 
salientamos que o debate sobre currículo, no curso de pedagogia, deve contemplar a educação matemática, entendida como,

\begin{abstract}
Uma área de conhecimento das ciências sociais e humanas, que estuda o ensino e a aprendizagem da matemática. De modo geral, poderíamos dizer que a Educação Matemática caracteriza- se como uma práxis que envolve o domínio do conteúdo específico (a matemática) e o domínio de ideias e processos pedagógicos relativos à transmissão/assimilação e/ou à apropriação/ construção do saber matemático escolar. (FIORENTINI; LORENZATO, 2006, p. 05).
\end{abstract}

A partir do que discute os autores, torna-se fundamental desenvolver práticas com os professores na sua formação inicial, de modo que vivenciem práticas educativas que ensinem os conceitos matemáticos, considerando a assertiva do ensino significativo, conectando saberes de suas experiências cotidianas conjugada com o conhecimento potencial, aquele que só a escola pode ofertar, conhecimentos esses que fazem as famílias buscarem a instituição escolar (YOUNG, 2007).

Diante deste contexto, o/a professor/a dos anos iniciais deve "assumir atitudes de insubordinação criativa em prol daqueles que educam e do conhecimento que produzem e promovem" (D’AMBROSIO; LOPES, 2015, p. 10). Esta subversão, a ser realizada na sala de aula, pode ser iniciada no âmbito dos cursos de Pedagogia no que se refere ao currículo, principalmente nos lugares reservados à matemática. Foi a partir de uma tentativa de insubordinar-se às tendências atuais e defasadas, durante o estágio, que nos propomos a discutir esse cenário e as possibilidades existentes para sua superação.

\title{
A experiência do estágio doutoral
}

As experiências do estágio doutoral são de grande impacto e importância na vida do/a pesquisador/a, pois é partindo do alinhamento entre a teoria e a prática, de maneira mais densa, que questões como o não-lugar da matemática, especificamente nesta pesquisa, vem à tona. Desse modo, considerando o conceito de experiência de Bondía (2002, p. 26), entendido como "aquilo que nos passa, que nos toca, que nos acontece, e, consequentemente, forma e transforma". Para o autor em tela, somente o sujeito da experiência está, portanto, aberto à sua própria transformação. Neste contexto, saliento a experiência do doutorado alinhada com o significado de deslumbramento com tantas aprendizagens, ora com os professores, outrora com os colegas; entre leituras, rodas de 
conversas com as estudantes da graduação, bem como com colegas docentes da educação básica. E é sobre a infinita imensidão de aprendizagens, que as pesquisas em Educação Matemática apresentam o que escrevemos aqui, como um filete a partir do nosso estágio em docência.

Quando a temática é formação de professores, o Estágio tem importância significativa. Zabalza (2014) afirma que etimologicamente a palavra estágio advém do latim medieval stagium, que significa "residência", "morada". Em inglês e espanhol, o termo é practium, estando aí, dialogicamente com a etimologia latina, a raiz do entendimento do Estágio como Prática. O pesquisador acrescenta que o neologismo latino foi "[...] adquirindo substância semântica mais por seu uso que por sua etimologia”. (ZABALZA, 2014, p. 37).

Entendendo o estágio como prática, nossa experiência com ele foi organizada com base na tríade formativa, que segundo Zanon (2003,p. 160) é uma composição entre estudantes, professore/ as da educação básica e professores/as formadores/as, "[...] o que é acrescido pela tríade é esse modo de interlocução que indica que os sujeitos interagem e refletem sobre um 〈algo〉 concernente a elementos e condições de 〈lá〉 da escola". Assim sendo, nossa tríade foi composta pelas 38 estudantes de Pedagogia que cursaram o componente curricular Fundamentos e Metodologia do Ensino de Matemática, duas professoras da educação básica, atuantes no $3^{\circ}$ e $5^{\circ}$ ano, de uma escola da rede municipal de São Luís, além da pesquisadora, que é doutoranda, e um professor licenciado em matemática na condição de formadores.

O grupo, formado a partir de uma diversidade, permitiu que a discussão colaborativa e a reflexão compartilhada fossem instigadas através da ação-reflexão-ação das concepções e das diferentes práticas sobre o ensino de matemática na Educação Infantil e Anos Iniciais do Ensino Fundamental. Nesse sentido, para uma ampliação dos horizontes investigativos, há de se considerar a troca de saberes entre docentes da rede pública de ensino, segmento no qual a maioria das egressas do curso de Pedagogia atuarão, de estudantes do curso de Pedagogia e dos docentes da universidade, haja vista ser essa uma oportunidade ímpar e essencial para ambas as partes, tendo com ação epistemológica norteadora a formação profissional fundamentada pela constante necessidade de qualificação das concepções teórico-prático, pois somente assim terão a consciência de que a educação passa por transformações políticas, sociais, culturais, pedagógicas e que essas influenciam diretamente nossas escolas, no espaço da sala de aula, assim como nas práticas pedagógicas. 
A formação de professores é um campo da educação que tem construído o conhecimento teórico-prático cada vez mais vinculado aos estudos, que, por sua vez, evidenciam que as concepções teóricas devem estar simultaneamente alicerçadas à prática como sendo dois aspectos que funcionam sempre em conformidade entre si. Nesse sentido, Tardif (2008) chama atenção ao ressaltar que ainda encontramos um campo vasto de conhecimentos teóricos acerca da formação inicial, que podem não estar em consonância com o ensino e distante da essência da prática docente, possibilitando, dessa forma, a não atuação com qualidade do professor em sala de aula.

A partir do que discute o autor, pensar a formação de professores deve ser precedido da condição de abrir horizontes para a necessidade de se buscar mecanismos de aprendizagem, que possibilitem ao futuro docente uma qualificação cada vez mais pautada no saber fazer. Desse modo, Imbernón (2011) esclarece que a carreira docente não deve ser pautada no processo de transmissão dos saberes científicos, tampouco se basear no ensino básico e reproduzir o saber dominante como sendo detentor de uma verdade absoluta. Mas que utilize uma didática eficaz considerando a apropriação do conhecimento, as transformações socioculturais, que influenciaram diretamente às escolas, bem como as diversas realidades em que o professor se encontra no tocante à sua ação docente.

Portanto, a partir das breves considerações, entendemos o estágio como pontapé basilar para que nos confrontemos como profissionais diante do que está posto, permitindo uma análise crítica dos caminhos pautados na prática reflexiva e fundamentada na ação-reflexão-ação. Destacamos, nesse sentido, a afirmativa de Zabalza (2014, p. 79): “[...] ao menos na educação superior deveríamos nos inclinar sem rodeios a uma visão da formação de sentido amplo, vinculando-a sempre a uma melhoria equilibrada e global das diversas dimensões dos sujeitos”. A partir dessa assertiva, fica nítido que o Estágio em docência, especificamente nesta experiência no doutorado, realiza o movimento de mobilizar os conhecimentos científicos elaborados ao longo do curso a fim de ressignificar sua prática docente.

\section{As possibilidades de aprendizagem em tríade}

Para o desenvolvimento do semestre, organizamos as $60 \mathrm{~h}$ em 3 unidades, cada uma com $20 \mathrm{~h}$. Na primeira unidade, tratamos da Educação Matemática na Educação Infantil e nos Anos Iniciais do Ensino Fundamental, comportando: a história da matemática e da educação matemática; os 
fundamentos da educação matemática; os conhecimentos matemáticos cotidianos e escolares. A segunda unidade foi definida como a matemática no currículo oficial da Educação Infantil e nos Anos Iniciais, na qual estudamos os Parâmetros Curriculares Nacionais- PCNs; os conteúdos matemáticos propostos pela BNCC, bem como as propostas da rede estadual do Maranhão e de São Luís. Para encerrar, na última unidade, discutimos a etnomatemática, a modelagem matemática, resolução de problemas, as múltiplas linguagens da criança na aprendizagem matemática, incluindo o brincar, os jogos, as brincadeiras, a literatura infantil, a música e o livro didático.

Os textos que subsidiaram as discussões foram entregues sempre com duas semanas de antecedência. $\mathrm{O}$ encontro era iniciado pelas alunas, apresentando os questionamentos dos textos, suas dúvidas. Em seguida, as professoras da educação básica apresentavam suas práticas docentes desenvolvidas com as crianças, relacionando-as com as temáticas discutidas naquele dia, por exemplo, números, geometria, álgebra, grandezas e medidas, estatística e probabilidade, dentre outros. Por fim, a pesquisadora doutoranda, junto com o professor de matemática, teciam considerações sobre os diversos fazeres apresentados, incutindo outras possibilidades pedagógicas, específicas, sobre as discussões da aula.

O nosso primeiro encontro foi marcado pelo memorial matemático. Nessa ocasião, cada estudante foi orientada, com antecedência de uma semana antes do início dos encontros presenciais, via plataforma digital, a elaborar um texto no qual contasse sua relação com a matemática, desde a educação infantil até o ensino superior. As discussões resultantes dessa atividade deveriam ser socializadas no primeiro encontro com o grupo. Estes relatos foram o ponto de partida para as discussões sobre as concepções de matemática, desde a época que elas estudaram até o período de formação de professores, incluindo contexto social do período, dentre outras questões que surgiam ao longo do semestre, constatação que emerge no relato abaixo:

\footnotetext{
Não considero o "não gostar de matemática" como uma opção pessoal. Pelo contrário, gostaria mesmo de gostar da matemática. Gostaria de decifrar cada enigma que se apresenta em forma de números e símbolos, mas não foi assim que a vida quis. $\mathrm{Ou}$, ao menos não foi assim que meus professores quiseram, nem houve motivação suficiente em mim. (TCR, 2019).

O primeiro momento negativo em relação a matemática foi nas séries iniciais, quando para não ficar sozinha em casa, precisei acompanhar meu primo no reforço escolar da professora mais temida do bairro, com o passar do tempo,
} 
o fato de nunca errar quando colocada em teste, fez com que a professora em questão decidisse me fazer uma pergunta muito além do meu nível/série de conhecimento, consequentemente apanhei de palmatória e os receios matemáticos começaram a surgir. (LPFC, 2019).

Por conta de tudo que passei na minha educação básica, acredito que já passou da hora do ensino da matemática em nosso país ser mais proveitoso e, isso envolve mudanças de práticas, métodos, atividades, capacitação de professores e aproveitamento dos conhecimentos prévios dos alunos. (ESB, 2019).

Fiorentino e Lorenzato (2012) consideram que os bloqueios e os traumas em relação à matemática geram conceitos, como os supracitados, estes foram causados, possivelmente, por aulas que suscitavam medo, fracasso ou humilhação, situações de aprendizagem nas quais as punições ganhavam a centralidade ao invés deste espaço ser destinado aos conhecimentos matemáticos. Assim sendo, as estudantes de Pedagogia têm em sua história de vida estudantil essas marcas, principalmente a matemática sendo concebida de forma isolada e distante da formação humana. Desse modo, não é oportuno fazer julgamentos sobre quem os formou, mas cabe refletir sobre a necessidade de romper com práticas de ensino que formam alunos desinteressados e com diversos traumas oriundos de uma prática fracassada do ensino de matemática.

Além das atividades mencionadas, organizamos uma roda de conversa sobre a matemática emocional, convidamos uma professora licenciada em Matemática, atuante na rede municipal de São Luís e na rede estadual, especialista em estudos que relacionam matemática e emoções, pois conforme afirma Inês Maria Gómez Chácon (2003, p. 25), sobre a importância do domínio afetivo do estudante no processo de ensino-aprendizagem, é "[...] pertinente não só aprofundar-se cada vez mais nas exigências cognitivas para a aprendizagem, mas também, e especialmente, nas exigências afetivas".

No caso das estudantes de Pedagogia, aprofundar-se nas exigências afetivas com a matemática, além de imprescindível é de caráter urgente, uma vez que estas profissionais formarão crianças, não podendo reproduzir medos, traumas e angústias acerca do ensino e da aprendizagem desta ciência, que também faz parte das linguagens que se dão no modo de processar o mundo. Partindo desse pressuposto, apresentamos às estudantes do componente curricular Fundamentos e Metodologias do Ensino de Matemática, frequentes no Curso de Pedagogia, $6^{\circ}$ período, turno noturno, da referida Universidade, as experiências dos docentes de uma turma de $3^{\circ}$ ano do ciclo 
de alfabetização. Ao aceitar o convite para partilhar as experiências, ressaltamos as dificuldades, os avanços e retrocessos enfrentados diariamente neste lugar, mas, sobretudo, de tornar visíveis as possibilidades que temos diante das necessidades que as crianças apresentam.

Múltiplas atividades foram propostas às estudantes, desde conversas com pedreiro, carpinteiro, pescador, artesão e rendeira, para sustentar as discussões sobre etnomatemática e modelagem matemática, aliadas aos textos, até mesmo a elaboração individual de um álbum de jogos relacionados aos conteúdos propostos pela BNCC, destacando os objetivos, os materiais e os textos instrucionais para jogar.

Para discutir a Educação de Jovens e Adultos, divididas em equipe, as alunas visitaram escolas. Quanto aos preparativos para a visita, discutimos textos e entregamos cartas de apresentação destinadas às professoras das turmas, além de orientações específicas de como conversar com elas sobre a matemática na sua formação, no seu uso cotidiano, seja no trabalho, seja em casa. Nesse sentido, a fim de ampliar o debate sobre ensino de matemática na EJA, uma professora, Mestra em Ensino de Ciências e Matemática, que pesquisa o ensino de matemática na EJA, docente da rede municipal de educação da cidade de Paço do Lumiar - município integrante da região metropolitana de São Luís -, com o referido debate aprofundou-se a temática junto aos envolvidos.

Ademais, tivemos uma oficina sobre estatística, probabilidade e combinatória na Educação Infantil e Anos Iniciais, desenvolvida em parceria com estudantes do curso de licenciatura em Matemática. Este momento foi muito interessante, sobretudo pelas aprendizagens entre estudantes de Pedagogia e de Matemática, com suas angústias sobre o que os espera no exercício da docência. Sobre este momento, uma estudante escreveu na avaliação:

Conhecer a realidade de outros cursos e dialogar com essa diferença, foi muito importante para que possamos entender que o processo educacional escolar está conectado e não deve haver uma desconexão entre anos/séries nas diferentes etapas, para que a aprendizagem aconteça de forma lógica, e não fragmentada, as reflexões levantadas foram de grande importância para que possamos perceber como as licenciaturas devem conversar e não se fechar em suas formas de fazer e pensar, a proposta de unir e agregar entre os cursos é um grande aprendizado. (APN, $8^{\circ}$ período, Pedagogia) 
Ao longo da história da educação, as distâncias entre as áreas de conhecimento se constituíram e provocaram um esvaziamento até hoje na formação inicial, que é refletida no processo de ensino e aprendizagem. Neste caso específico, é importante lembrar que saber matemática não é suficiente para ensinar matemática, bem como saber sobre pedagogia não é satisfatório para ensinar matemática na educação infantil e nos anos iniciais, sendo imprescindível um diálogo entre as referidas áreas.

A realização dos ateliês pedagógicos foi proposta como atividade de encerramento do semestre, objetivando vivenciar atividades que favorecessem os processos de ensino e aprendizagem de matemática na educação infantil e nos anos iniciais do ensino fundamental. Para tanto, a turma foi dividida em sete grupos, cada grupo apresentou os fundamentos da sua metodologia, demonstrando como utilizar na sala de aula, de modo que todas as metodologias contemplassem alguma necessidade educativa especial, ou seja, que fossem inclusivas. As temáticas contempladas foram: história da matemática, etnomatemática, modelagem matemática, tecnologias digitais, literatura infantil, jogos e brincadeiras. As equipes ficaram livres para escolher uma das unidades temáticas para aprofundar, a saber: números, álgebra, geometria, grandezas e medidas, estatística, probabilidade e combinatória.

A última atividade foi o memorial da disciplina, arquivo que as estudantes deveriam contar o percurso da disciplina e as contribuições da mesma em sua formação profissional, além de avaliar. Neste contexto, ao sistematizar os memoriais, percebemos que quase a totalidade da turma questionou a quantidade de atividades, as estudantes acrescentaram que as demandas das outras disciplinas terminaram por sobrecarregá-las, conforme destaca a discente MCMS “[...] a crítica que tenho a fazer sobre a disciplina seria a metodologia utilizada nas atividades, pois eram muitas, fiquei sobrecarregada com as atividades que eram para ser entregues, tendo em vista as outras disciplinas que também estou cursando no período”.

Assim sendo, cabe salientar que o processo formativo envolve constante avaliações, não sendo diferente no desenvolvimento dos estágios. Abaixo outro trecho comum nos memoriais:

Eu critico o fato dessa disciplina ser apenas no sexto período, pois ela deveria ser ofertada logo nos primeiros períodos, com certeza nos prepararia melhor para quando chegássemos no estágio. (AKLA).

\section{plurais}


A minha visão mudou muito ao longo da disciplina. Meu olhar acerca de como a criança gostaria de estudar ficou mais aflorado, conhecer e reconhecer a importância do brincar possibilidade metodológica na educação infantil. Eu particularmente não gostava de matemática e achava que estudar sobre os Fundamentos e Metodologias do ensino da Matemática seria bem difícil, e que eu não conseguiria compreender a ideia central que a disciplina passaria, mas ao final, me surpreendi, a disciplina contemplou não só minhas expectativas como aluna que se viu gostando da matemática, mas como futura professora que viu no que foi trabalhado, uma forma de desmistificar a ideia de que ensinar matemática é chato e que matemática é difícil. (VPC).

Esta disciplina mudou meu olhar sobre a matemática, pois antes a via como uma disciplina difícil de ser aprendida e de ser ensinada, pois em meu ensino fundamental e médio não houve uma contextualização da mesma. Acredito que os textos e discussões realizadas em sala de aula me ajudarão bastante em minha prática docente futuramente. (KCC).

Com as professoras convidadas, tivemos experiências muito relevantes nos mostrando como trabalhar com os alunos circunferência, círculo, de uma maneira prática, construtiva para o professor e para aluno um dia de grande aproveitamento para mim, de uma forma tão simples ela nos mostrou a grandeza de se aplicar a matemática por meio da prática, do fazer tocando, cortando, medindo e não somente ouvindo conteúdo. (MCFGC).

Outro momento bastante significativo, foi nossa visita na turma de Educação de Jovens e Adultos. Temos três disciplinas de EJA em uma delas nos direcionou uma visita, como observação. Mas, a visita realizada nesta disciplina foi diferente, pois fomos de forma mais propositiva e participativa, além de observar a professora e alunos com o contato com a matemática, podemos ouvir os alunos sobre suas dificuldades e seus crescimentos com a disciplina. (SSG).

Pude ampliar meu modo de ver a escola, a realidade do professor, as necessidades de aprendizagem do aluno; ascendeu ainda mais meu sentimento de "é isso que eu quero para mim, ser professora", mesmo em meio aos problemas educacionais brasileiros. (AMLC).

A partir do corpus apresentado, é importante reiterar que o processo de formação inicial é uma etapa de provocações, de diferentes aprendizagens e de possibilidades para ressignificar as práticas a serem adotadas, neste caso, especificamente, na educação infantil e nos anos iniciais do ensino fundamental, no que concerne ao ensino de matemática. Diante do contexto, Tozetto 
(2010, p. 13) assegura que a criticidade do professor o torna um intelectual apto a desenvolver competências necessárias à sua profissão, em que "[...] uma ação docente que contemple o ato de educar em sua amplitude e complexidade. O profissional crítico faz escolhas subsidiado no conhecimento científico, constrói seu conhecimento considerando a diversidade social, cultural, econômica, humana".

\section{Entre a universidade e a sala de aula do ciclo de alfabetização: o olhar de quem ocupa os dois lugares}

A oportunidade de compartilhar com as estudantes do Curso de Pedagogia da UFMA, as formas pelas quais desenvolvemos a prática educativa, relacionada ao componente curricular de Matemática com as crianças do $3^{\circ}$ ano do ciclo de alfabetização, possibilitou diversas experiências entre as estudantes da graduação e nós, que já estamos no exercício da docência.

Dessa forma, conhecer a sala de aula pelos olhos de quem a vive $20 \mathrm{~h}$ semanais ininterruptos, é um processo muito interessante para a formação inicial dessas futuras profissionais, já que possibilita conhecer com mais propriedade como a experiência de sala de aula é um aspecto relevante na construção e reconstrução do conhecimento, levando em conta a criticidade, o nível de aprendizagem, a metodologia, o conhecimento prévio e o contexto sociocultural individual, entre outros.

A partir desse contexto, conforme Bannell (2001, p. 122) “[...] cada sala de aula está inserida em um contexto sociocultural, que é plural, marcado pela diversidade de grupos e classes sociais, visões de mundo, valores, crenças, padrões de comportamentos, etc., uma diversidade que está refletida na sala de aula". Tendo como base a discussão proposta, essa diversidade deve ser respeitada também na educação superior, baseada diretamente no contexto sociocultural de cada aluna, no qual se devem escolher os melhores caminhos para uma prática docente cada vez mais significativa e ressignificada, atendendo as necessidades do alunado.

Explicamos para as estudantes que em nosso caso específico, as dificuldades são encontradas em três frentes: didática, pedagógica e estrutural. Na falta de recursos didáticos, o livro é o recurso didático mais utilizado, e alinhado ao trabalho com materiais alternativos, recicláveis, a partir da lógica de empréstimos de outros recursos com as colegas, (mas que a realidade de uma escola anexo, na periferia, não é tão simples), realidade que nos impulsiona para que busquemos

\section{plurais}


enfrentar, de modo a ofertar um conhecimento poderoso (YOUNG, 2007) para as crianças, partindo do pressuposto de uma construção constante a partir da insubordinação criativa.

Partindo desse contexto, conforme Costoldi e Polinarski (2009, p. 2), "[...] os recursos didáticos são de fundamental importância no processo de desenvolvimento cognitivo do aluno", em que aproxima o estudante do contexto social em que se encontra inserido, o que facilita a assimilação da aprendizagem de maneira mais efetiva, tornando o conhecimento mais flexível a outras formas de aprender. Assim sendo, nas aulas quando as discussões eram em torno dos recursos didáticos, as estudantes questionavam sempre a ludicidade, (porque é natural, durante a formação inicial no curso de Pedagogia, este debate). Essa oportunidade de diálogo nos permitiu mostrar que ao chegarmos na escola da rede pública, as coisas não são tão bonitas assim, é necessário muito enfretamento, temos que estar disponíveis para buscar alternativas, porque nos faltam suportes estruturais, pedagógicos e didáticos.

Nesta acepção, entendemos que ouvir e discutir os nossos relatos de experiências como professoras dos anos iniciais do ensino fundamental, pertencendo à mesma área de formação e a mesma instituição, é fundamental, no sentido de construírem a consciência de que a formação inicial exige uma troca entre arcabouço teórico e as vivências de quem vive o atendimento direto com as crianças. Desse modo, a docência exige uma construção, uma reinvenção constante, conforme Freire assegura (1991, p. 71) "[...] ninguém começa a ser professor numa certa terça-feira às 4 horas da tarde... ninguém nasce professor ou marcado para ser professor. A gente se forma educador permanentemente na prática e na reflexão sobre a prática”. Assim como,

\footnotetext{
Não existe uma única prática educativa em relação à Matemática, existem vários caminhos, que são questionados a todo momento, pois apresentam alcances e limites. O professor, conhecedor de sua turma e dos saberes que circulam em sua aula, precisa ter flexibilidade e autonomia para gerir esses acontecimentos (PASSOS; NACARATO, 2018, p. 127).
}

Portanto, a troca feita por meio dos diálogos, nos debates, nos conflitos de ideias, integra a nossa construção e só nos fez perceber o quão válido é a aproximação das escolas com a universidade pública. Esse contato dinâmico e flexível possibilita construir espaços de reflexão-ação-reflexão objetivando qualificar práticas docentes, tanto das estudantes em processo de formação e futuras docentes quanto dos professores da educação básica, porque nós, também, aprendemos com elas, 
com os convidados e formadores, entendendo que nenhum de nós sabe mais que o outro. Apenas ocupamos lugares diferentes.

\section{Considerações finais}

Embora tenha havido muitos esforços, algumas lacunas certamente devem ter ficado no percurso. E neste percurso foram muitas as adversidades, sobretudo na administração da carga horária $60 \mathrm{~h}$, já que são muitos obstáculos para contemplar a ementa e desenvolver de maneira exitosa um programa que contemple o básico de uma formação inicial, considerando que este é o único componente curricular que discute o ensino de matemática na estrutura do projeto pedagógico do curso de Pedagogia.

Durante esta experiência, foi possível vivenciar as mais variadas dificuldades que a condição de docente formadora nos coloca, a saber: lidar com os problemas cotidianos das alunas, entre as incertezas sobre a escolha da profissão e os conflitos de professoras com anos de docência, ressignificando ali e agora sua prática a partir das leituras e dos debates das aulas; de outro lado, a desistência de alunas por terem que escolher entre estudar e trabalhar, além dos conflitos teóricos, o cenário educacional do município, do estado, do país, daí a importância de se ter uma clareza teórico-metodológica para tecer diálogos e saber conviver com as adversidades.

Os encontros e desencontros com diversos estudos teórico-metodológicos nos conduziram a propor atividades desafiadoras e impulsionadoras, que vão desde a curiosidade à vontade de buscar o novo, capazes de aguçarem as percepções e interesses das crianças, porque entendemos que as professoras precisam antes ter experimentado tais estímulos para só então recriarem em suas práticas docentes, utilizando da imaginação e da polissemia didático-pedagógica. Desse modo, estes são aspectos essenciais na educação de crianças, mas sem desprezar os conceitos a serem explorados, sempre atentas a eles e buscando a melhor maneira de explorá-los, neste caso, centrados na educação matemática.

Portanto, a nossa tentativa, enquanto docente formadora, vivendo um processo de formação continuada no doutoramento, foi instigar e vivenciar as ricas discussões e orientações dos professores envolvidos, tendo consciência de que cada turma é única, e destacando que cada programa acertado com um grupo, certamente precisará de mudanças para outro e assim sucessivamente.

\section{plurais}




\section{REFERÊNCIAS}

AUGÉ, M. Não-lugares: introdução a uma antropologia da supermodernidade. Campinas: Papirus, 1994. (Coleção Travessia do Século).

BANNELL, R. Formação discursiva do professor e a (re) construção crítica do saber pedagógico. Movimento: revista da Faculdade de Educação da Universidade Federal Fluminense, Niterói, n. 4, set. 2001. Disponível em: <https://periodicos.uff.br/revistamovimento/article/view/32434>. Acesso em: 10 jun. 2020.

BONDÍA, J L. Notas sobre a experiência e o saber de experiência. Tradução: João Wanderley Geraldi. Revista Brasileira de Educação, n. 19, p. 20-28, abr. 2002. Disponível em: < https://www.scielo.br/cgi-bin/wxis.exe/iah/>. Acesso em: 10 jun. 2020.

BRASIL. Decreto $\mathrm{n}^{\circ}$ 32.606, de 23 de abril de 1953. Autoriza o funcionamento dos cursos de filosofia, letras neo-latinas, geografia e história e pedagogia da Faculdade de Filosofia de São Luiz do Maranhão. Diário Oficial da União, Brasília, DF, 28 abr. 1953. Seção 1. Disponível em: <https:// www2.camara.leg.br/legin/fed/decret/1950-1959/decreto-32606-23-abril-1953-329726-publi- cacaooriginal-1-pe.html>. Acesso em: 10 jun. 2020 .

BRASIL. Decreto $n^{\circ}$ 39.663, de 28 de Julho de 1956. Concede reconhecimento aos cursos de geografia e história, letras neo-latinas e pedagogia, da Faculdade de Filosofia de São Luis, Estado do Maranhão. Diário Oficial da União, Brasília, DF, 30 jul. 1956. Seção 1. Disponível em: < https://www2.camara.leg.br/legin/fed/decret/1950-1959/decreto-39663-28-julho-1956-334221-norma-pe.html >. Acesso em: 10 jun. 2020.

BRASIL. Ministério da educação. Base Nacional Comum Curricular (BNCC). Brasília, DF: Ministério da Educação, 2017. Disponível em: $<$ http://basenacionalcomum. mec.gov.br/images/BNCC_EI_EF_110518_versaofinal_site.pdf $>$. Acesso em: 10 jun. 2020 .

BRASIL. Resolução CNE/CP n ${ }^{\circ}$ 1, de 15 de maio de 2006. Institui Diretrizes Curriculares Nacionais para o Curso de Graduação em Pedagogia, licenciatura. Diário Oficial da União, Brasília, DF, 16 maio 2006. Seção 1. Disponível em: <http://portal.mec.gov.br/ cne/arquivos/pdf/rcp01_06.pdf>. Acesso em: 10 jun. 2020. 
BRASIL. Resolução CNE/CP n 1, de 18 de fevereiro de 2002. Institui Diretrizes Curriculares Nacionais para a Formação de Professores da EducaçãoBásica, em nível superior, curso de licenciatura, de graduação plena. Diário Oficial da União, Brasília, DF, 18 fev. 2002. . Disponível em: <http://portal.mec.gov.br/seesp/arquivos/pdf/res1_2.pdf>. Acesso em: 10 jun. 2020.

BRASIL. Resolução CNE/CP n 2, de 20 de dezembro de 2019. Define as Diretrizes Curriculares Nacionais para a Formação Inicial de Professores para a Educação Básica e institui a Base Nacional Comum para a Formação Inicial de Professores da Educação Básica (BNC-Formação). Diário Oficial da União, Brasília, 15 abr. 2019. Seção 1. Disponível em: <http://portal.mec.gov.br/docman/dezembro-2019-pdf/135951-rcp002-19/file>. Acesso em: 10 jun. 2020.

BRASIL. Resolução $n^{\circ} 2$, de $1^{\circ}$ de Julho de 2015. Define as Diretrizes Curriculares Nacionais para a formação inicial em nível superior (cursos de licenciatura, cursos de formação pedagógica para graduados e cursos de segunda licenciatura) e para a formação continuada. Diário Oficial da União, Brasília, 2 jul. 2015. Seção 1. Disponível em: $<$ http://portal.mec.gov.br/docman/ agosto-2017-pdf/70431-res-cne-cp-002-03072015pdf/file>. Acesso em: 10 jun. 2020.

BUTTIMER, A. Campo de Movimento y sentido del lugar. In: RAMÓN, M. D. G. (org.) Teoria y Método em la Geografia Anglosajona. Barcelona, Ariel, 1985.

CHACÓN, I.M.G. Matemática emocional: os afetos na aprendizagem matemática. Porto Alegre: Artmed, 2003.

COSTOLDI, R.; POLINARSKI, C. A. Utilização de recursos didático- pedagógicos na motivação da aprendizagem. In: Simpósio Internacional de Ensino e Tecnologia, 1., 2009.

D’AMBROSIO, B. S; LOPES, C. E. Insubordinação Criativa: um convite à reinvenção do educador matemático. Bolema, Rio Claro (SP), v. 29, n. 51, p. 117, abril de 2015.

FIORENTINI, D.; LORENZATO, S. Investigação em Educação Matemática: percursos teóricos metodológicos. Campinas, SP: Autores associados, 2006.

FIORENTINI, D.; LORENZATO, S. Investigação em educação Matemática: percursos teóricos e metodológicos. 3. ed. Campinas, SP: Autores Associados, 2012. 
FREIRE, P. Educação na cidade. São Paulo: Cortez Editora, 1991.

IMBERNÓN, F. Formação docente e profissional: formar-se para a mudança e a incerteza. 9. ed. São Paulo: Cortez, 2011.

LIMA, C. N. M. F. L; NACARATO, A.M. A investigação da própria prática: mobilização e apropriação de saberes profissionais em Matemática .Educação em Revista, Belo Horizonte, v.25, n. 2, p.241-266, ago. 2009. Disponível em: <http:/www.scielo.br/ scielo.php?script=sc i_arttext\&pid=S0102-46982009000200011\&lng=en\&nrm=iso $>$. Acesso em: 10 jun. 2020.

MARANHÃO. Decreto ${ }^{\circ} 21$, de 15 de abril de 1890. Reorganisa o ensino público do Estado. Palácio do Governo do Estado do Maranhão, Maranhão, 15 abr. 1890. Disponível em: <http://casas.cultura.ma.gov.br/portal/sgc/modulos/sgc_bpbl/acervo_digital/ arq_ad/20141106160213.pdf $>$. Acesso em: 10 jun. 2020.

PASSOS, C. NACARATO, A. Trajetória e perspectivas para o ensino de Matemática nos anos iniciais. Estudos Avançados, 32(94), 119-135, 2018. Disponível em: $<$ https:// doi.org/10.1590/s010340142018.3294.0010 >. Acesso em: 10 jun. 2020.

PONTE, J. P. Investigar a nossa prática. In: GTI - Grupo de Trabalho e Investigação (Org). Reflectir e investigar sobre a prática profissional. Portugal: Associação de professores de Matemática, 2002. p. 5-55.

SANTOS, M. J. C.; MATOS, F. C. C. A insubordinação criativa na formação contínua do pedagogo para o ensino da matemática: os subalternos falam?. RenCiMa: Revista de Ensino de Ciências e Matemática. Edição Especial - Insubordinação Criativa nas Pesquisas Qualitativas em Educação Matemática v. 8, n. 4, 2017.

SILVA, T. T. Documentos de identidade: uma introdução às teorias do currículo. Belo Horizonte: Autêntica, 2006.

TARDIF, M. Saberes docentes e formação profissional. Petrópolis-RJ: Editora Vozes, 2008.

TOZETTO, S. S. Trabalho docente e suas relações com o saber. In: docente: saberes e práticas. Curitiba: CRV, 2010. p. 21-51. . Trabalho 
TUAN, Yi-Fu. Espaço e lugar: a perspectiva da experiência. São Paulo: DIFEL, 1983.

YOUNG, M. Para que servem as escolas?. Educ. Soc., Campinas, v. 28, n. 101, p.

1287-1302, set./dez. 2007. Disponível em: $<$ http://www.cedes.unicamp.br $>$. Acesso em: 10 jun. 2020.

\section{ZABALZA, M. A. O estágio e as práticas em contextos profissionais na educação} universitária. São Paulo: Cortez, 2014.

ZANON, L. B. Interações de Licenciandos formadores e professores na elaboração conceitual de práticas docentes: módulos triádicos na licenciatura de Química. 2003, 282 p. Tese em Educação) - Programa de Pós graducação em Educação. Universidade Metodista de Piracicaba, Piracicaba, SP, 2003. Disponível em: <https://www.btdeq.ufscar.br/teses-e-dissertacoes/interacoes-de-licenciadas-formadores-e-professores-na-elaboracao-conceitual-de-pratica-docente-modulos-triadicos-na-licenciatura-de-quimica $>$. Acesso em: 10 jun. 2020.

Recebido em: 30 de junho de 2020.

Inserido em: 10 de agosto de 2020.

Esta obra está licenciada com uma Licença Creative Commons Atribuição 4.0 Internacional. 